Published in final edited form as:

Science. 2014 May 23; 344(6186): 809-810. doi:10.1126/science.1252743.

\title{
Inequalities in Science
}

\author{
Y. $\mathbf{X i e}^{1,2, *}$ \\ ${ }^{1}$ Institute for Social Research and the Department of Sociology, University of Michigan, Ann \\ Arbor, MI 48104 \\ ${ }^{2}$ Center for Social Research, Peking University, Beijing 100871, China
}

\begin{abstract}
Inequalities in scientists' contributions to science and their rewards have always been very high. There are good reasons to propose that inequalities in science across research institutions and across individual scientists have increased in recent years. In the meantime, however, globalization and internet technology have narrowed inequalities in science across nations and facilitated the expansion of science and rapid production of scientific discoveries through international collaborative networks.
\end{abstract}

In recent years, academic scholarship, along with public discourse, has become increasingly preoccupied with social and economic inequality, which has risen in many countries. Thus, it is surprising that more research attention has not been paid to the large inequalities in the world of science. In this article, I present an overview of these inequalities, focusing on their social origins, trends, consequences, and contextual sources.

Before doing this, let me define "inequalities in science." In this essay, "science" refers primarily to basic, natural science, although most of my general conclusions are also applicable to the social and applied sciences. By "inequalities," I mean differences across scientists in three major domains: resources, research outcomes, and monetary or nonmonetary rewards. While inequalities ultimately exist at the individual level, they are influenced by contexts.

\section{Inequality as an Intrinsic Property of Science}

In his 1963 book, Little Science, Big Science (1), Derek Price observed that inequality in science is inherently high and called it "undemocracy" $(1$, p.59), meaning that a great scientist's value for science far exceeds that of ordinary scientists. While a few elite scientists make fundamental contributions, most carry out routine tasks. Scientific outputs and rewards are much more unequally distributed than other well-being outcomes, such as education, earnings, or health $(1,2)$. Where status is concerned, very high inequality is recognized and accepted among practicing scientists, who compete for extraordinary honors such as a Nobel Prize (3).

“Correspondence to: yuxie@umich.edu [Phone: 734-936-0039]. 
One source of inequality in science is what Robert Merton called the "Matthew effect" (4), referring to Matthew 25:29 in the Christian Bible: "For unto every one that hath shall be given, and he shall have abundance: but from him that hath not shall be taken even that which he hath." The Matthew effect means that eminent scientists receive disproportionately greater recognition and rewards for their contributions to science than lesser-known scientists for comparable contributions. As a result, a talented few can parlay early successes into resources for future successes, such as university support, research grants, graduate students, and productive collaborators, accumulating advantages over time. While science rewards all participants through a skewed tier system with the most significant rewards going to the top-performers, science has certain attributes that resemble a "winner-takes-all" market: high visibility of top winners, a large contestant base, accumulation of advantages, absence of physical or cultural boundaries, and intense competition $(4,5)$. Thus, many scientists feel that merely being good at their jobs is not enough. Competition is all about priority -- a scientist's claim to be the first to make a big discovery $(3,6)$.

Whatever their cause, high inequality in scientific rewards is often defended on two grounds. First, given the positive externalities of science (7), the more skewed rewards are, the greater the incentive for outstanding scientific work that will ultimately benefit all of humanity ( 8 , 9). Second, as a profession, science is supposed to practice what Merton called universalism (10), a norm which dictates that evaluation in science be based solely on merit rather than on functionally irrelevant factors such as gender, race, nationality, age, religion, and class (2, 10). This merit-based system makes high inequality seem fair and acceptable.

\section{Changes in Science}

Before the nineteenth century, science was mainly a small-scale, personal pursuit enjoyed by a few leisure-class amateurs. Over the next two centuries, however, it expanded enormously into an institution characterized by certain distinctive features: a huge, well-paid, professional workforce; large-scale government and industrial support; reliance on the university as institution; graduate student labor; and a peer-review, flat system of evaluation (7). More recently, advances in internet technology have facilitated the rapid dissemination of research results to a vast readership (11).

While these features of the new, "big science" have made scientific production faster and more voluminous than in the old "little science," they have also rendered the evaluation of scientists less substance-specific and more "numbers-based." Scientists today are increasingly likely to be judged by whatever numbers they can generate in terms of publications, citations, research grants, prestigious awards, research team size, and memberships in elite academies than by their actual scientific contributions (7). This tendency may have been amplified by increasing specialization, such that scientists in one specialty area find it difficult to understand content in another. In addition, university administrators, faced with uncertainties and competing demands for scarce resources, have strong incentives to use externally generated and validated indicators (12). 


\section{Has Inequality in Science Increased?}

More empirical research is needed to answer this question. I believe that two trends have caused inequality in science to rise over time. First, given science's concentration of high rewards to a select few, the large increase in the population of scientists (7) means a higher concentration over time and thus an increase in inequality. That is, winners in science have relatively more to gain today than those in the past. Second, the tendency towards numbersbased evaluations has exacerbated the Matthew effect, a mechanism for generating inequality in science.

As with income inequality in the U.S. in general, inequality in academics' salaries has trended upwards, both between private and public universities and among universities of each type (13). For individual academic scientists, salary inequality has increased substantially since the 1970s, across all ranks and diverse fields (14).

\section{Illustrations: Inequality in Science at Work}

Here are two examples of intensified inequality in science today. First, many new science $\mathrm{Ph}$.D. recipients from American universities in recent years have been unable to obtain regular academic positions and instead are taking post-doctoral fellowships, or other forms of non-tenure track employment (7). (One source of this problem may be the large supply of well-trained foreign students and immigrant scientists (7).) The work by these temporary employees contributes directly to the success of senior scientists who head large scientific teams.

Second, internet technology, a globalized economy, inexpensive air transportation, and relatively peaceful world politics have created an unprecedentedly interconnected world (15). In this new global environment, a successful scientist filled with ideas at a prestigious university in America or Europe can design studies and have them carried out by dependent collaborators in less developed countries, such as China, where labor-intensive scientific work can be conducted at lower costs. Such collaborations are complementary and can lead to mutual benefits (16), while at the same time amplifying inequality across individual scientists, as more successful scientists are much more likely than less successful ones to be centrally located in global collaborative networks facilitated by new communication technologies.

\section{Contextual Sources of Inequality in Science}

Scientists are situated within and affected by research institutions, which, in turn, are located in and affected by different societies. Hence, inequalities across individual scientists are generated and reinforced by social forces at contextual levels. Below, I will discuss contextual sources at two levels: institution and country.

The importance of institutional environment to scientists is well documented $(2,17,18)$. Scientists affiliated with prestigious institutions are more productive and better rewarded than those who are not. Hence, greater institution-level inequality serves to intensify the individual-level inequality of scientists. 
There is some evidence that institution-level inequality in resources has increased over time. In Fig. 1, I present the 1990-2010 trends in the Gini coefficients for (i) total research expenditure, (ii) federal research expenditure, and (iii) endowment for U.S. universities (19). The Gini is a commonly used measure for inequality, ranging from 0 for absolute equality, to 1 for absolute inequality. As Fig. 1 shows, institutional inequalities in the three resource measures have all been very high throughout the period, with most Gini coefficients well above 0.70 . Despite already high levels of inequality, however, the Gini coefficients trended upwards during the period. By the end of the period, the Gini in federal research expenditure had reached 0.82, with Ginis in total research expenditure and endowment trending respectively to 0.81 and 0.76 . Part of the reason for the increases was an expansion in institutions that participate in research. If we restrict our analysis to a limited set of universities that have always been active in research, there is no clear trend.

Large country-level differences in scientific activities have long been noted (20). Historically, the world center of science has shifted several times, from Renaissance Italy to England to France and to Germany, before crossing Atlantic to the United States in the twentieth century (21). In the past nine decades, America has dominated the world of science (7). However, just as between-country income inequality has narrowed in the world, mostly due to a rise of income in China (22), between-country differences in science have also narrowed, thanks to the globalization of science $(7,16)$. Measuring between-country inequality in science is not easy. One possibility is to track changes in research output number of published articles - as a crude measure of scientific activity. In Fig.2, I present trends between 1990 and 2011 in science/engineering publications that are tracked by Thomson Reuters' InCites and Essential Science Indicators databases by major countries. I use the U.S. productivity level as a reference so that all lines indicate ratios of a country's productivity to that of the U.S. While the relative increase in research productivity was modest and non-monotonic for Germany, Japan, and the United Kingdom, the increase was pronounced for India and dramatic for China. By 2011, China's article output was about two thirds that of the U.S., a remarkable surge given its low 5\% level back in 1990. Of course, the comparison of total productivity by country in Fig. 2 is misleading because it does not control for population or economy size. The main focus here is on trends, which point towards the narrowing of country differences, mainly due to the growth of science in China.

\section{Conclusion}

Inequality has been, and will always be, an intrinsic feature of science. Few scientists produce truly path-breaking work. Those scientists with exceptional achievements are highly recognized in science and society at large and receive generous financial resources and institutional support for their work.

Inequalities in science in recent years have been affected by two concurrent changes - the globalization and expansion of science and the increasingly widespread use of internet technology. These two forces have conflicting effects on different levels of inequality in science. At the levels of individual scientist and institution, they have tended to intensify inequality. At the country level, they have narrowed it. However, we need to remember that the most significant consequences of these two forces for science have been positive overall: 
the large expansion of science as a collective enterprise and the resulting rapid progress of science on a global scale (16).

\section{Supplementary Material}

Refer to Web version on PubMed Central for supplementary material.

\section{Acknowledgments}

Data used in this article are documented in the Supplementary Materials posted online. Financial support for this research was provided by the Natural Science Foundation of China (grant no. 71373012), Peking University, and the Population Studies Center at the University of Michigan, which receives core support from the National Institute of Child Health and Human Development (R24HD041028). The author is grateful to Cindy Glovinsky, Jingwei Hu, Qing Lai, Chunni Zhang for research assistance.

\section{References and Notes}

1. Price, DJ. Little Science, Big Science. New York: Columbia Univ. Press; 1963.

2. Cole, J.; Cole, S. Social Stratification in Science. Chicago: Univ. Chicago Press; 1973.

3. Zuckerman, H. Scientific Elite, Nobel Laureates in the United States. New York: Free Press; 1977.

4. Merton RK. The Matthew effect in science: The reward and communication system of science. Science. 1968; 199:55-63.

5. Frank, RH.; Cook, PJ. The Winner-Take-All Society. New York: Penguin; 1995.

6. Merton RK. Priorities in scientific discovery: A chapter in the sociology of science. American Sociological Review. 1957; 22(6):635-659.

7. Xie, Y.; Killewald, AA. Is American Science in Decline?. Cambridge, MA: Harvard Univ. Press; 2012.

8. Lazear EP, Rosen S. Rank-order tournaments as optimum labor contracts. Journal of Political Economy. 1981; 89(5):841-864.

9. Ehrenberg RG, Bognanno ML. Do tournaments have incentive effects? Journal of Political Economy. 1990; 98(6):1307-1324.

10. Merton, RK. The normative structure of science. Reprinted (1973) as pp. 267-78. In: Merton, R., editor. The Sociology of Science: Theoretical and Empirical Investigations. Chicago: Univ. Chicago Press; 1973.

11. Evans JA. Electronic publication and the narrowing of science and scholarship. Science. 2008; 321:395-399. [PubMed: 18635800]

12. Rodríguez-Ruiz O. The citation indexes and the quantification of knowledge. Journal of Educational Administration. 2009; 47(2):250-266.

13. Ehrenberg RG. Studying ourselves: the academic labor market. Journal of Labor Economics. 2003; 21(2):267-287.

14. Stephan, P. How Economics Shapes Science. Cambridge, MA: Harvard Univ. Press; 2012. p. 41

15. Friedman, T. The World Is Flat, A Brief History of the Twenty-First Century. New York: Farrar, Straus, and Giroux; 2005.

16. Xie Y. Is American science in decline? Issues in Science and Technology, Spring Issue. 2014

17. Allison PD, Long JS. Departmental effects on scientific productivity. American Sociological Review. 1990; 55:469-478.

18. Cole, JR. The Great American University: Its Rise to Preeminence, Its Indispensable National Role, Why It Must Be Protected. New York: Public Affairs; 2009.

19. Source is: http://mup.asu.edu/research_data.html.

20. King DA. The scientific impact of nations. Nature. 2004; 430:311-316. [PubMed: 15254529]

21. Ben-David, J. The Scientist's Role in Society: A Comparative Study. Chicago: Univ. Chicago Press; 1971. 
22. Firebaugh, G. The New Geography of Global Income Inequality. Cambridge, MA: Harvard Univ. Press; 2003. 


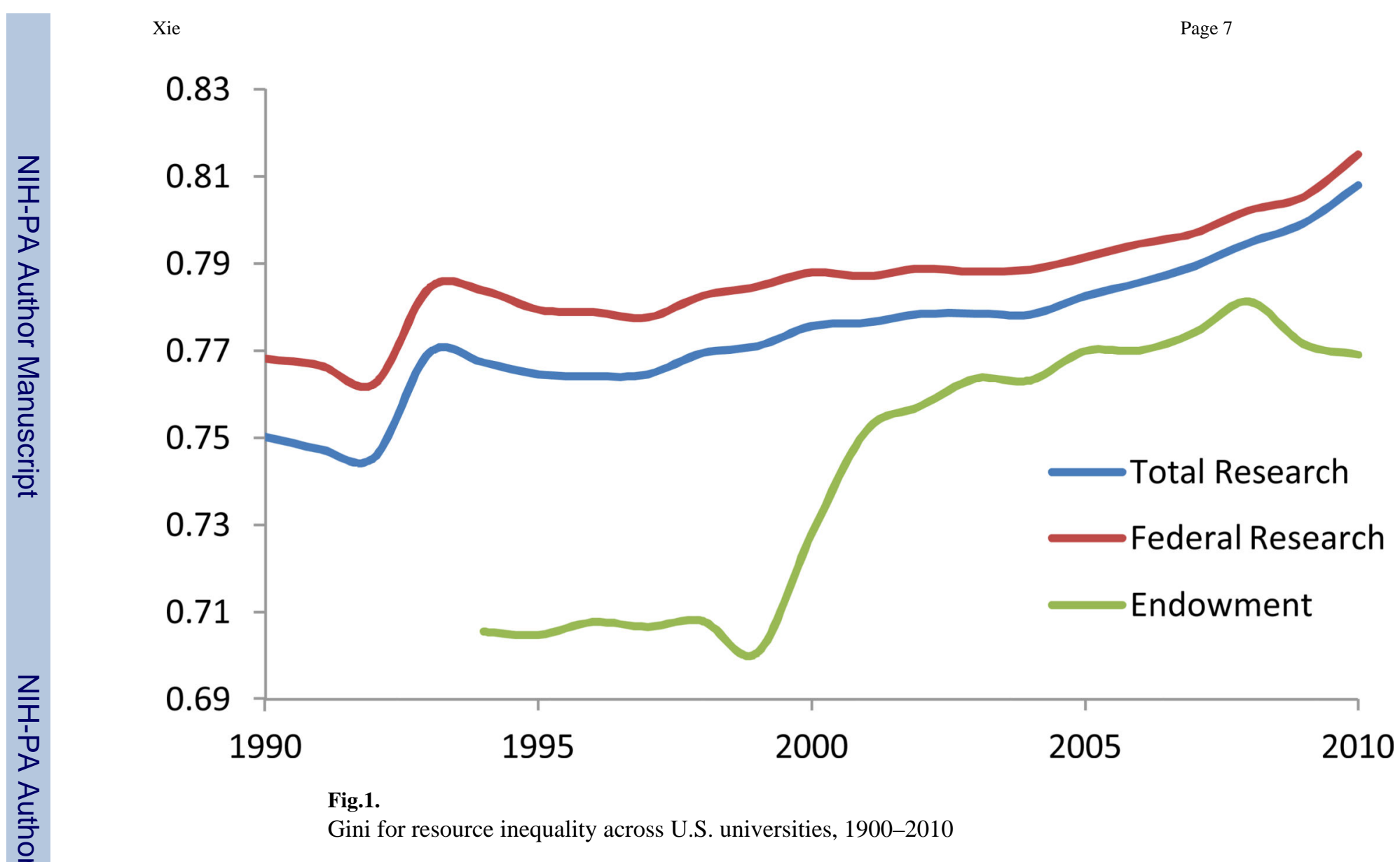




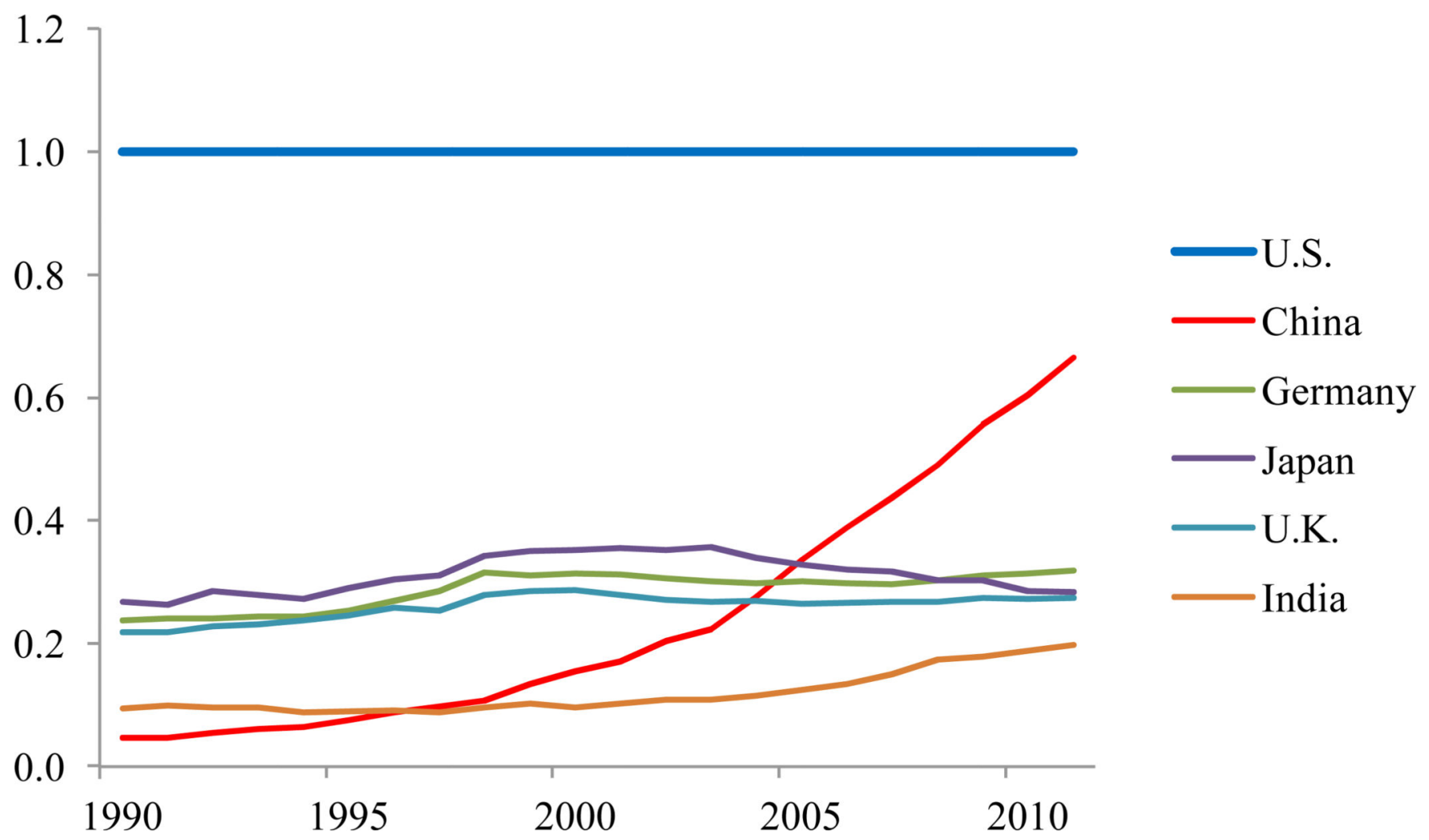

Fig. 2.

Ratios in total number of science/engineering articles of a country to that of the U.S., 19902011. Source: Thomson Reuters' InCites and Essential Science Indicators databases. 